\title{
LIPOMAS GIGANTES
}

\section{GIANTS LIPOMAS}

\author{
Pietro Accetta, TCBC-RJ ${ }^{1}$ \\ Italo Accetta, TCBC-RJ ${ }^{2}$ \\ Eduardo C. Vassallo, TCBC-RJ ${ }^{3}$ \\ Marcio Milman ${ }^{4}$ \\ Aline Martins de Souza ${ }^{4}$ \\ Antonio Carlos Accetta ${ }^{5}$
}

\section{INTRODUÇÃO}

Os lipomas são neoplasias benignas do tecido adiposo e constituem-se nos tumores mais freqüentes de origem mesenquimal. Os lipomas verdadeiros são encapsulados e, não se sabe a razão, localizam-se preferencialmente no tecido subcutâneo da metade superior do corpo humano, embora possam surgir em qualquer local onde o tecido gorduroso esteja normalmente presente. Incidem mais nas mulheres e são, quase sempre, solitários apesar da forma múltipla, também mais freqüente no sexo feminino, que guarda relação com uma predisposição genética. Não são comuns em crianças e não apresentam relação com a obesidade.

Os lipomas por si só costumam ser indolores, mas, dependendo da sua localização, podem desencadear uma série de sintomas relacionados com a compressão ou obstrução de órgãos e estruturas vizinhas. O crescimento dos lipomas é incomum, pois seu tamanho costuma limitar-se a $2 \mathrm{~cm}$ de diâmetro, não ultrapassando uma área de $10 \mathrm{~cm}^{2}$. Ocasionalmente podem atingir grandes proporções, caracterizando os chamados lipomas gigantes, cujos relatos no passado eram um pouco mais freqüentes, mas atualmente quase não são observados na prática clínica.

O presente trabalho apresenta dois casos de lipomas gigantes da região glútea operados, consecutivamente, no Serviço de Cirurgia Geral do Hospital Universitário Antonio Pedro.

\section{RELATO DOS CASOS}

Caso 1: Homem branco, 65 anos, nacionalidade chilena, prontuário 511375. Apresentava uma enorme tumoração na região glútea direita com evolução superior a dez anos e crescimento mais evidente nos últimos três anos. Relatava que, em 1974, havia se submetido a tratamento com várias injeções de corticóides nessa região (Figura 1). Relatava dor e queimação local, mas sua principal queixa relacionava-se com a dificuldade de sentar e deitar em decúbito dorsal. Ao exame, a massa era sólida, tinha consistência firme, superfície bocelada e não apresentava sopros ou batimentos arteriais. Ocupava toda a região glútea direita e estendia-se acima da crista ilíaca ASD. Foi submetido a exames de Raios-X simples e ultra-sonografia. A tomografia computadorizada mostrou volumosa massa sólida com densidade de gordura heterogênea, pequenas calcificações e sem plano de clivagem bem definido. O tumor ocupava áreas superficiais e profundas. Foi preparado e submetido a cirurgia.

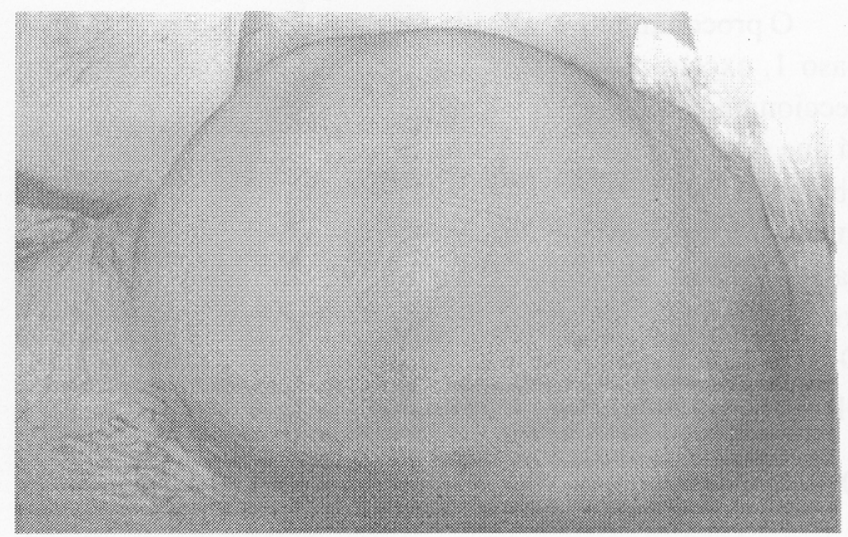

Figura 1-Lipoma gigante ocupando a região glútea direita (caso 1)

1. Professor Titular do Departamento de Cirurgia da FM-UFF. Chefe do Serviço de Cirurgia Geral do HU Antonio Pedro.

2. Professor Titular do Departamento de Cirurgia da FM.UFF.

3. Professor Adjunto do Departamento de Cirurgia da FM-UFF.

4. Médico Residente do HU Antonio Pedro.

5. Acadêmico de Medicina da UFF.

Recebido em 24/4/98

Aceito para publicação em 10/8/98

Trabalho realizado no Serviço de Cirurgia Geral do Hospital Universitário Antonio Pedro da Universidade Federal Fluminense, Niterói, RJ. 
A via de acesso foi uma incisão dupla de aproximadamente $20 \mathrm{~cm}$, elípticas, com retirada de retalho de pele para facilitar sua sutura. Observamos grande tumoração amarelada, trilobulada, com o lobo superior situando-se no tecido celular subcutâneo, acima do músculo glúteo máximo e os dois mais inferiores em posição inframuscular. Para facilitar a liberação do tumor, a inserção lateral desse músculo foi seccionada próximo ao trocanter maior do fêmur, rebatendo-o medialmente permitindo a abordagem aos planos profundos. Retirado o tumor, a musculatura foi reinserida e a ferida fechada após a drenagem da grande loja com dreno aspirativo. O paciente evoluiu bem e o dreno foi retirado após 48 horas, quando ocorreu a alta hospitalar. O laudo histopatológico foi de lipoma com áreas de necrose, fibrose reativa, calcificação e pseudocisto. O tumor pesou $3,9 \mathrm{~kg}$.

Caso 2: Mulher branca, 42 anos, natural do estado do Rio de Janeiro, prontuário 438117. Apresentava grande tumoração na região glútea direita, com evolução de dois anos e que vinha aumentando progressivamente de tamanho. Sem relato de trauma local, não referia queixas relacionadas ao tumor a não ser as de ordem estética. A massa era sólida, de consistência amolecida, indolor à palpação e não apresentava sopros ou batimentos arteriais. A tomografia computadorizada mostrou um grande tumor com aumento da ecotextura em plano gorduroso com a parte externa apresentando limites imprecisos e ocupando regiões supra e inframusculares (Figura 2). Preparada, foi submetida a cirurgia.

O procedimento realizado foi semelhante ao descrito no caso 1, exceto pelo menor tamanho das incisões. Também seccionamos a inserção lateral do músculo glúteo máximo, já que o tumor situava-se parte no tecido subcutâneo e parte abaixo da musculatura. O tumor foi removido por inteiro, o músculo reinserido e a ferida operatória fechada após colocação de dreno aspirativo. A paciente evoluiu bem e o dreno foi retirado com 48 horas, quando ocorreu a alta hospitalar. O laudo histopatológico foi de tumor lipomatoso atípico (subtipo esclerosante). A peça pesou $3,1 \mathrm{~kg}$.

\section{DISCUSSÃO}

A caracterização de um lipoma gigante ainda não está estabelecida com clareza, uma vez que alguns desses tumores podem ser considerados grandes e desencadeadores de sintomas se localizados em determinados locais como intestino, coração, SNC. Noutras regiões, esse mesmos tumores seriam considerados pequenos e quase sempre assintomáticos. Evidentemente, ao darmos a denominação de gigante a um tumor, a associação com uma massa volumosa é automática. Nesse sentido, uma revisão da literatura permite sugerir que, para ser classificado como gigante, o lipoma deve ter pelo menos $10 \mathrm{~cm}$ de diâmetro ou um peso mínimo de $1.000 \mathrm{~g} .{ }^{1}$

Sabe-se que a incidência dos lipomas pequenos é muito freqüente, mas os chamados gigantes são bem mais raros, ${ }^{1,2}$
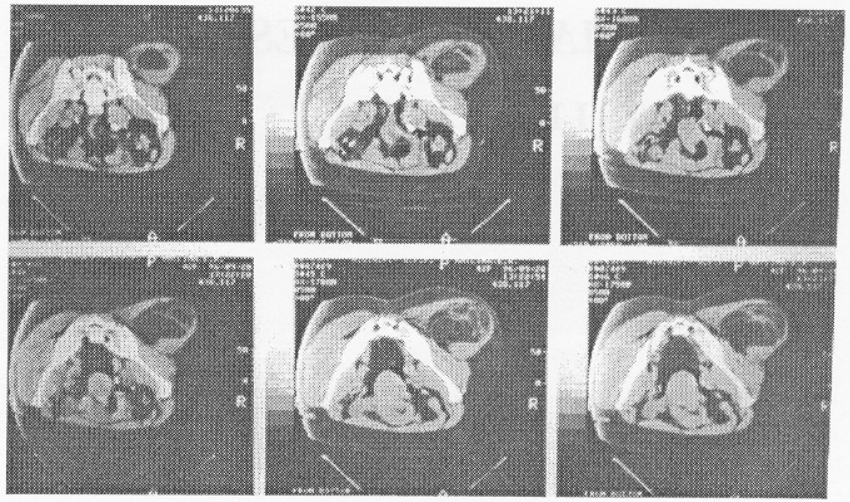

Figura 2 - Lipoma gigante da região glútea direita (caso 2). Detathes de exame por TC

muito embora se observe na prática clínica uma ocorrência possivelmente maior que a registrada na literatura, em função de casos pessoais isolados que nunca chegaram às publicações especializadas.

Ao que parece, esses casos eram mais comuns no passado, onde vamos encontrar registros de tumores imensos que chegaram a pesar $22,7 \mathrm{~kg}$ e $12,5 \mathrm{~kg}$, localizados na região escapular e cérvico-dorsal, respectivamente. ${ }^{1}$ Atualmente, quase não encontramos mais relatos desse tipo, apesar das recentes observações publicadas a propósito de um enorme lipoma retroperitoneal operado, que pesou $13 \mathrm{~kg} .{ }^{2}$

O mecanismo de crescimento descontrolado desses tumores é desconhecido. Com a ocorrência de grandes lipomas em regiões que sofreram traumas fechados importantes surgiu a chamada teoria traumática. ${ }^{3}$ Essa teoria, que permanece controvertida, procura explicar a formação do grande lipoma a partir de hematoma pós-traumático em área de tecido mole ou da protusão de tecido gorduroso normal através de efrações na fáscia de sustentação. Entretanto, como tais tumorações não possuem cápsula, se enquadram melhor na definição de falsos lipomas, o que não é o caso dos relatos que apresentamos.

O diagnóstico é inicialmente clínico, mas deve ser confirmado por exames de imagem. A ultra-sonografia é um bom método, mas a tomografia computadorizada é superior porque fornece com mais nitidez a dimensão real do tumor, a área ocupada e sua relação com estruturas vizinhas.

O valor da biópsia prévia nesses casos é muito discutível, se realizada com a finalidade de detectar doença maligna. $\mathrm{Na}$ verdade a consideramos contra-indicada e defendemos a exerése completa do tumor, por entender que só o exame da peça inteira permite que o patologista estabeleça o diagnóstico anatomopatológico correto.

O tratamento dos lipomas gigantes é cirúrgico e consiste na sua total remoção sob visão direta. Alguns cirurgiões vêm defendendo a lipoaspiração como forma de tratamento, o que para nós é uma indicação equivocada do método, ainda que aceitável em alguns casos de pseudolipomas, ${ }^{3}$ desde que sejam consideradas as repercurssões metabólicas que podem resultar 
das macrolipoaspirações. ${ }^{4}$ As complicações da lipoaspiração, como a formação de grandes hematomas e recidiva causada pela retirada incompleta do tumor, tornam a excisão cirúrgica mais adequada, sobretudo quando tais tumores, situando-se em planos mais profundos, podem comprometer músculos e envolver estruturas nobres como grandes vasos e nervos. Ademais, existe sempre a possibilidade de transformação sarcomatosa desses lipomas, sobretudo quando localizados em tecidos mais profundos. ${ }^{5}$
Nos dois casos apresentados, os lipomas, além de muito grandes, eram profundos, dando a impressão de que sua origem estava abaixo do músculo glúteo máximo e que a localização subcutânea parcial do tumor era apenas uma projeção que se fazia por entre as fibras musculares. A secção da inserção lateral da musculatura permitiu uma ampla exposição do campo operatório e facilitou, sobremaneira, a cirurgia e a visualização do nervo isquiático, que era e estrutura mais nobre em ambos os casos.

\begin{abstract}
The authors report two cases of giants lipomas in the gluteal region with 3,9 and 3,1 kg. They make a brief epidemiological presentation and consider diagnosis and treatment. They believe that CT scan is the best image method, as it provides more information about size and relationship with surrounding structures. They are against biopsies and lipoaspiration but stand up for the total exeresis as the best option of treatment.
\end{abstract}

Key Words: Lipoma; Surgery.

\section{REFERÊNCIAS}

1. Sanchez MR, Golomb FM, Moy JA, et al - Giant lipoma: Case report and review of the literature. J Am Acad Dermatol 1993; 28(2):266-8.

2. Ntshaykolo P, Trujillo $\mathrm{P}$, Bussone $\mathrm{M}$ - Lipome rétro-péritonéal géant. J Chir (Paris), 1996; 133(3):148-9.

3. David LR, DeFranzo A, Marks M, et al - Posttraumatic pseudolipoma. J Trauma, 1996; 40(3):396-400.

4. Modolin M, Ferreira MC, Leme RB, et al - Parâmetros de avaliação nas macrolipoaspirações. Rev Col Bras Cir 1997; 24(6):409-15.

5. Pitcher ME, Karalis G, Howell J, et al - Deep lipoma in the differential diagnosis of soft tissue tumours. Br J Surg 1994; 81:1.140.
ENDEREÇO PARA CORRESPONDÊNCIA

Dr. Pietro Accetta

Rua Maris e Barros, 48/601

24220-121- Niterói - RJ 